\title{
Nearshore internal bores and turbulent mixing in southern Monterey Bay
}

\author{
Ryan K. Walter, ${ }^{1}$ C. Brock Woodson, ${ }^{1}$ Robert S. Arthur, ${ }^{1}$ Oliver B. Fringer, ${ }^{1}$ \\ and Stephen G. Monismith ${ }^{1}$ \\ Received 4 April 2012; revised 30 May 2012; accepted 7 June 2012; published 25 July 2012.
}

[1] We observed transient stratification and mixing events associated with nearshore internal bores in southern Monterey Bay using an array of instruments with high spatial and temporal resolution. The arrival of the bores is characterized by surging masses of dense (cold) water that tend to stratify the water column. The bore is followed by a gradual drop in the temperature throughout the water column over several hours (defined here as the bore period) until a sharp warm-front relaxation, followed by high frequency temperature fluctuations, returns the column back to nearly its original state (defined here as the mixing period). Mixing periods revealed increased temperature variance at high frequencies $(\omega>\bar{N})$, as well as a greater percentage of events where dynamic instabilities may be present $(R i<0.25)$, suggesting active mixing of the stratified water column. Turbulent dissipation rates in the stratified interior during the mixing period, estimated using the technique of isopycnal slope spectra, revealed mean values the same order of magnitude as near-bed bottom-generated turbulence. Observations indicate that local shear-produced turbulent kinetic energy by the warm front relaxations dominates mixing in the stratified interior. The non-canonical nature of these bore and relaxation events is also investigated with a numerical model, and the dynamics are shown to depend on the internal Iribarren number. Our results suggest that nearshore internal bores interacting with local bathymetry dramatically alter local dynamics and mixing in the nearshore with important ecological implications.

Citation: Walter, R. K., C. B. Woodson, R. S. Arthur, O. B. Fringer, and S. G. Monismith (2012), Nearshore internal bores and turbulent mixing in southern Monterey Bay, J. Geophys. Res., 117, C07017, doi:10.1029/2012JC008115.

\section{Introduction}

[2] Energetic nonlinear internal waves are ubiquitous features in the nearshore coastal ocean, defined here as the innermost portion of the continental shelf extending from the shoreline to about $2 \mathrm{~km}$ offshore, where internal waves often appear bore-like rather than wave-like [e.g., Pineda, 1994; Leichter et al., 1996; Storlazzi et al., 2003; Scotti and Pineda, 2004; Nam and Send, 2011; Davis and Monismith, 2011; Wong et al., 2012]. Numerical studies of internal wave shoaling [e.g., Venayagamoorthy and Fringer, 2007] have identified the formation of internal bores (boluses) that act to drive dense water across the adjacent shelf where they can impact coastal ecosystems. In effect, the nearshore coastal ocean can be thought of as the "swash zone" for larger-scale internal wavefields on the continental shelf. From a practical standpoint, these flows are observed to be important for

\footnotetext{
${ }^{1}$ Environmental Fluid Mechanics Laboratory, Stanford University, Stanford, California, USA.

Corresponding author: R. K. Walter, Environmental Fluid Mechanics Laboratory, Stanford University, 473 Via Ortega, Room M-15, MC 4020, Stanford, CA 94305, USA. (rwalter@stanford.edu)

C2012. American Geophysical Union. All Rights Reserved. 0148-0227/12/2012JC008115
}

cross-shelf transport and exchange of nutrients, sediments, and contaminants [Wolanski and Pickard, 1983; Leichter et al., 1996; Boehm et al., 2002]; larval transport [Pineda, 1991, 1994, 1995, 1999]; and turbulent mixing and dissipation [Venayagamoorthy and Fringer, 2007; Nam and Send, 2011].

[3] In shallow waters, as nonlinear waves of depression shoal along a sloping bottom, they morph into waves of elevation near the point where the pycnocline is located at the midpoint between the surface and the bottom [Grimshaw et al., 1999; Scotti and Pineda, 2004; Shroyer et al., 2009]. These bottom-trapped internal waves of elevation are characterized by upslope surging fronts, followed by dense (cold) waters [c.f. Nam and Send, 2011]. They have also been referred to as elevation-type solitary waves with trapped (cold) cores, as well as solibores to emphasize the combination of wave-like and bore-like properties [e.g., Klymak and Moum, 2003; Hosegood and van Haren, 2004; Scotti and Pineda, 2004; Nam and Send, 2011]. Here, we will refer to nonlinear cold water surges as bores. This term emphasizes the shock-like nature of the change, and is used by analogy to discontinuous changes in depth in unsteady shallow water free surface flows [Stoker, 1948].

[4] The typical (referred to here as canonical) bore on a sloping shelf has an initial steep face (often called a front) 
that is responsible for the bulk of the temperature drop associated with the bore event. This front is followed by a gradual tapered warming where the temperature returns to roughly its original state slowly over several hours [e.g., Leichter et al., 1996; Hosegood and van Haren, 2004]. In this case, instabilities and mixing associated with the bore event are often confined to the initial propagation of the core and trailing internal waves. For the canonical case, no strong warm front is observed.

[5] The bore events observed in this study do not follow the canonical description and are defined here as noncanonical. While the initial bore still provides a sharp drop in temperature, the temperature continues to decrease slowly over several hours. This cooling is followed by an abrupt warm front and high frequency fluctuations that return the water column to roughly its original temperature. The warm front can be viewed as the relaxation of the bores downslope [e.g., Pineda, 1994]. As the cold bores propagate onshore into warmer water, a front is formed between the cold bore water and the displaced warm water. Eventually the bore, like swash on a beach, comes to rest, and the currents reverse, as the cold waters (followed by displaced warm waters) rush back offshore near the bottom [Pineda, 1994]. As we will show, the canonical versus non-canonical nature of these bores is dependent on local bathymetry and internal wave properties.

[6] The first objective of this study is to understand the general characteristics and fate of bores in the nearshore environment of southern Monterey Bay. Internal bores are common along many continental margins [Shea and Broenkow, 1982; Pineda, 1991, 1994, 1995, 1999; Leichter et al., 1996; Colosi et al., 2001; Klymak and Moum, 2003; Storlazzi et al., 2003; Hosegood and van Haren, 2004; Nam and Send, 2011]. Yet, detailed observations of internal bores in the nearshore are rare, mainly due to the lack of measurements with sufficiently high temporal and spatial resolution to adequately resolve the dynamics [c.f. Scotti and Pineda, 2004; Nam and Send, 2011]. Here, we take advantage of detailed measurements of cold bores in southern Monterey Bay in order to better understand their dynamics and effect on the nearshore coastal environment.

[7] The second objective is to quantify local turbulent dissipation and mixing by internal bores in the nearshore environment of southern Monterey Bay. Continental shelves and the nearshore environment are thought to be an important, but highly variable, contributor to the dissipation of turbulent kinetic energy (TKE) in the ocean [Carter et al., 2005]. Likewise, the irreversible mixing of momentum is often linked to the cascade of energy at large-scales through an internal wave continuum to small-scale turbulence [Kunze et al., 2002; Klymak and Moum, 2007a, 2007b]. Consequently, shoaling internal waves provide a significant energy transfer pathway, where instabilities and breaking are directly linked to turbulent dissipation. Recent studies have estimated turbulent dissipation rates in stratified flows with success using horizontal gradients of vertical isotherm displacements, or isopycnal slopes [Klymak and Moum, 2007a, 2007b; Woodson et al., 2011]. Here, we use the isopycnal slope spectra method to assess turbulent dissipation and mixing due to localized shear-induced turbulence generated by the observed bore events.

[8] The overall goal of this study is to examine how internal bores affect nearshore circulation dynamics, local turbulent mixing, and the consequent impacts on nearshore coastal ecosystems. Here, we focus on local water column dynamics and mixing in the nearshore environment of southern Monterey Bay. Regional forcing and generation mechanisms, as well as energetics, will be investigated in future studies. In section 2, we introduce the field site, sampling strategy, and data processing methods. Section 3 describes the general features of the bores and warm front relaxations including propagation characteristics, effects on the density field, and detailed structure. This is followed by a quantitative comparison of the temperature variance and the potential for turbulent mixing between the bore and relaxation events. Finally, we employ the technique of isopycnal slope spectra to estimate turbulent dissipation rates associated with the relaxation events. Section 4 provides a discussion of the results including an examination of the non-canonical nature of the bores using a numerical model, as well as an examination of turbulence in the stratified interior and nearshore environment. Section 5 summarizes the findings and highlights potential implications.

\section{Site Description and Methods}

\subsection{Experimental Setup}

[9] Monterey Bay, located along the central coast of California, is a semi-enclosed embayment and features one of the largest submarine canyons on the west coast of the United States (Figure 1a) [Carter et al., 2005]. Large amplitude internal waves are a common feature in and around the canyon, with isopycnal displacements reaching hundreds of meters [e.g., Breaker and Broenkow, 1994; Petruncio et al., 1998; Kunze et al., 2002]. Currents are dominated by the $M_{2}(\sim 12.42 \mathrm{~h}$ period) tidal component with barotropic velocities reaching up to $0.2 \mathrm{~m} / \mathrm{s}$ on the shelf [Breaker and Broenkow, 1994], although baroclinic tidal velocities are important near the head of the Monterey Canyon [Carter, 2010]. The southern portion of the bay, which is the location of this study, is protected from dominant swell and not significantly influenced by diurnal winds so that the currents are not strongly correlated with surface wave and windforcing (C. B. Woodson, Spatio-temporal variation in crossshelf exchange across Monterey Bay, CA, submitted to Journal of Physical Oceanography, 2012).

[10] Moored instrument arrays were deployed from 1 to 16 May 2010 in southern Monterey Bay in order to capture internal bore activity. Moorings were arranged in approximately a right triangle offshore of Hopkins Marine Station (HMS - Stanford University, Pacific Grove, CA) located in the southern end of the bay and just inside of the Monterey Peninsula (Figure 1b). The main/center (MN) and along-shore (AS) moorings were deployed on the $15 \mathrm{~m}$ isobath about $100 \mathrm{~m}$ apart, while the cross-shore (XS) mooring was placed approximately $100 \mathrm{~m}$ offshore of MN near the $20 \mathrm{~m}$ isobath (Figure 1b). Each mooring was equipped with a dense vertical arrangement of SBE39 and SBE56 temperature loggers ( $\mathrm{n} \geq 6$ at each mooring) throughout the water column. MN and XS each had a bottom-mounted SBE 37 conductivitytemperature-depth (CTD) logger. An RDI $1200 \mathrm{kHz}$ Workhorse acoustic Doppler current profiler (ADCP) was deployed at the MN mooring sampling in fast-ping Mode 12 with $0.25 \mathrm{~m}$ vertical bin spacing. The ADCP was leveled by divers in order to minimize instrument tilt errors. 


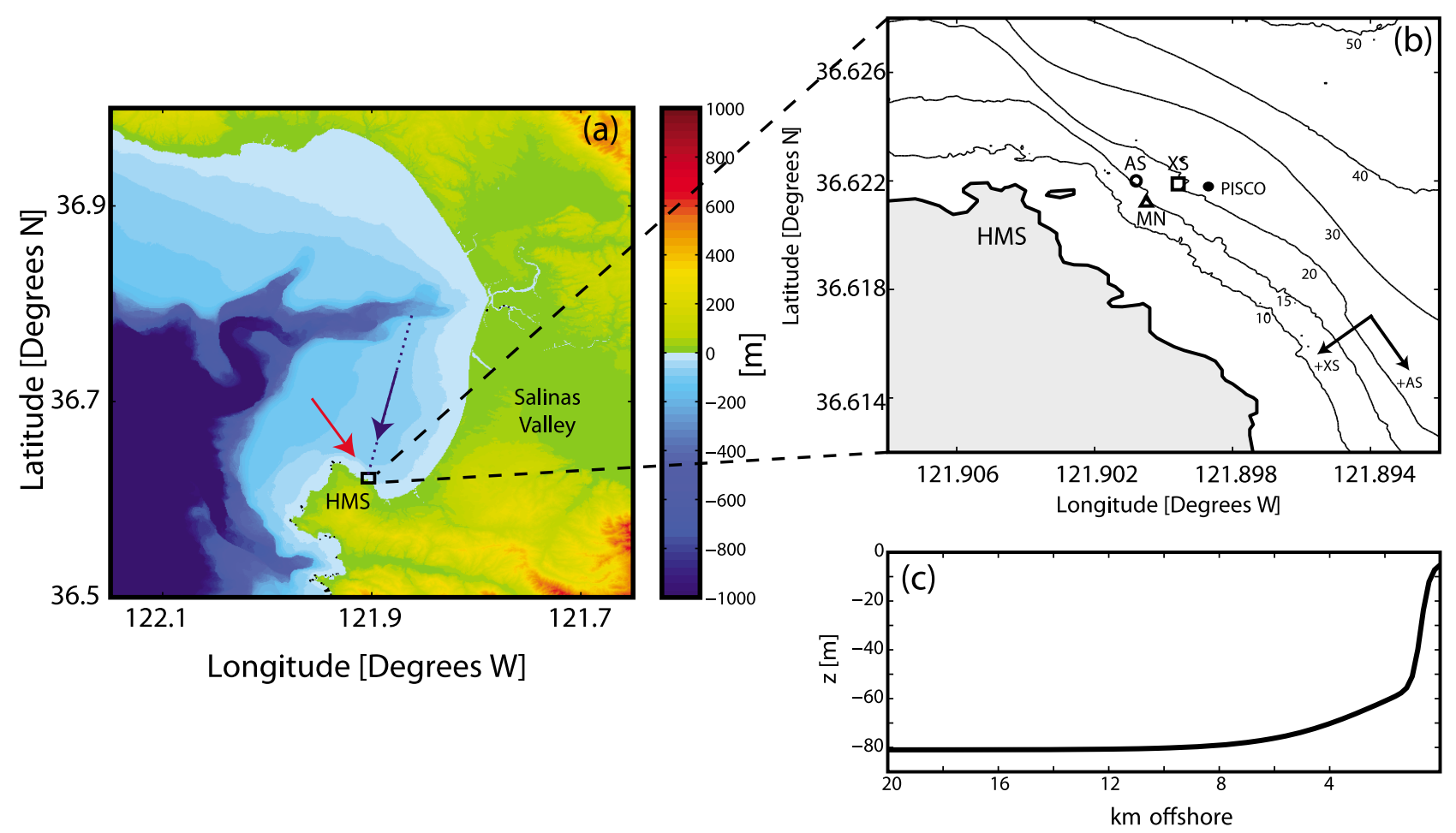

Figure 1. (a) Bathymetry and topography of the Monterey Bay region with the study site indicated by a black box and median bore (blue) and relaxation (red) headings shown. (b) Nearshore study site with mooring locations ( $\mathrm{MN}$ - triangle, AS - circle, XS - square). Bathymetry $(10,15,20,30,40,50 \mathrm{~m}$ isobaths) shown along with the location of Hopkins Marine Station (HMS - Stanford University). The filled circle is the long-term PISCO HMS mooring. (c) Section along the median observed propagation path of the bores (Figure 1a, dotted blue line) showing the bathymetry used in the numerical model for the non-canonical case (Section 4.1).

[11] In order to capture the high temporal variability associated with the bores and estimate dissipation rates using isopycnal slope spectra, the temperature loggers and ADCP at the $\mathrm{MN}$ mooring were programmed to maximize the sampling frequency while maintaining enough battery life to capture a sufficient number of bore and relaxation events (10 to 16 May 2010, $\mathrm{n}=7$ events). Details of mooring configurations, sampling rates, and periods of deployment are given in Table 1. In what follows, detailed analyses of individual bore events $(n=7)$ presented will be during the one-week sampling period when all three moorings collected data (10 to 16 May 2010), while general characteristics of the bore arrival will include results over the entire study period (1 to 16 May 2010). Longer time series collected in this region as part of PISCO (Partnership for Interdisciplinary Studies of Coastal Oceans), albeit with less temporal and spatial resolution than the current study, indicate that these results are representative of longer time scales (Woodson, submitted manuscript, 2012).

\subsection{Data Analysis}

\subsubsection{Data Processing}

[12] Velocity measurements from the ADCP were rotated into cross-shore $(u)$, along-shore $(v)$, and vertical $(w)$ velocity

Table 1. Mooring Configurations, Instrument Details, and Sampling Specifics

\begin{tabular}{|c|c|c|c|c|c|c|}
\hline \multirow[b]{2}{*}{$\begin{array}{l}\text { Mooring } \\
\text { ID }\end{array}$} & \multicolumn{2}{|c|}{ Location } & \multirow[b]{2}{*}{$\begin{array}{l}\text { Water Depth } \\
\text { (m) }\end{array}$} & \multirow[b]{2}{*}{$\begin{array}{l}\text { Instrument Depth } \\
\qquad(\mathrm{mab})\end{array}$} & \multirow[b]{2}{*}{$\begin{array}{l}\text { Sampling Interval } \\
\text { (s) }\end{array}$} & \multirow[b]{2}{*}{$\begin{array}{l}\text { Sampling } \\
\text { Period }\end{array}$} \\
\hline & $\begin{array}{l}\text { Latitude } \\
\left({ }^{\circ} \mathrm{N}\right)\end{array}$ & $\begin{array}{c}\text { Longitude } \\
\left({ }^{\circ} \mathrm{W}\right)\end{array}$ & & & & \\
\hline \multicolumn{7}{|c|}{ Thermistors (SBE39 and SBE56*) } \\
\hline XS & 36.6219 & 121.8997 & 20 & $2,4,6,8,10,12,14$ & 6 & 1 to 16 May 2010 \\
\hline AS & 36.622 & 121.9008 & 15 & $4,6,8,10,12$ & 6 & 1 to 16 May 2010 \\
\hline $\mathrm{MN}$ & 36.6212 & 121.9005 & 15 & $2,3^{*}, 4,6,10,12$ & $1 *, 3$ & 10 to 16 May 2010 \\
\hline \multicolumn{7}{|c|}{$C T D s(S B E 37)$} \\
\hline XS & 36.6219 & 121.8997 & 20 & 0 & 30 & 1 to 16 May 2010 \\
\hline $\mathrm{MN}$ & 36.6212 & 121.9005 & 15 & 0 & 30 & 10 to 16 May 2010 \\
\hline \multicolumn{7}{|c|}{$A D C P(R D I 1200 \mathrm{kHz})$} \\
\hline $\mathrm{MN}$ & 36.6212 & 121.9005 & 15 & $0,0.25 \mathrm{~m}$ bins & 1 (mode 12$)$ & 10 to 16 May 2010 \\
\hline
\end{tabular}


components using principal axes obtained from an ADCP associated with a long-term PISCO mooring at the site (Figure 1b). Here, $u$ velocities are defined as positive onshore, $v$ velocities positive along-shore headed into the bay ( southeastward), and $w$ velocities positive upward (Figure 1b). During the summer upwelling season, salinity variations in Monterey Bay are minimal so that density is largely controlled by temperature [e.g., Woodson et al., 2009, 2011]. Analysis of the bottom-mounted CTD data showed that small changes in salinity varied linearly with temperature $\left(R^{2}=0.93\right)$. Therefore, densities at all depths were calculated using the observed temperature and the derived linear relationship from the CTD measurements for salinity as a function of temperature.

[13] Spectral calculations are performed using the fast Fourier transform (FFT). For the time series of interest, the time-mean was removed and the series was linearly detrended. Next, the data were split into smaller segments, which were then zero padded to achieve the next power of two for the FFT and to increase frequency resolution. The choice of window length signified a compromise between the increased number of degrees of freedom (DOF) for each spectral estimate, decreased frequency resolution, and length of the original record. Each segment was multiplied by a Hamming window with $50 \%$ overlap to decrease spectral leakage. Spectral densities were computed using the FFT, and segments were block averaged. Confidence intervals (95\%) were calculated using a chi-square variable analysis and the "equivalent" number of DOF [Emery and Thomson, 2004].

\subsubsection{General Characteristics and Propagation}

[14] The triangular configuration of the moorings was utilized to calculate the speed $(c)$ and direction of propagation $(\Theta)$ of the bore features following the analysis of Pineda [1999] and Woodson et al. [2011]. Phase speeds and directions were determined with errors less than $1 \%$, based on the spatial design and the sampling frequency of the instruments [e.g., Lee, 1961; Woodson et al., 2011]. Estimates of the bore and warm front relaxation speeds were determined using the $4 \mathrm{~m}$ above bottom (mab) temperature logger at all moorings. Similar phase speeds were found using loggers at other heights. Bores were defined as large, step-like drops in the temperature field $\left(\Delta T \sim-0.5^{\circ} \mathrm{C}\right.$, cooling in $\left.1 \mathrm{~min}\right)$, throughout the lower portion ( 0 to $10 \mathrm{mab}$ ) of the water column. Likewise, relaxations of the bores were classified as even larger step-like increases in the temperature field $(\Delta T \geq$ $1^{\circ} \mathrm{C}$, warming in $5 \mathrm{~min}$ ) throughout the water column ( 0 to $12 \mathrm{mab}$ ). Ambient currents were taken into account by removing the depth-averaged (barotropic) current in the direction of the bore/relaxation $\left(U_{\text {depth }}\right)$ for an hour prior to the arrival of the bore/front. Thus, the actual propagation speed of the bore, $c=c_{o b s}-U_{\text {depth }}$, was found using the observed propagation speed $\left(\mathrm{c}_{\mathrm{obs}}\right)$ in the presence of a barotropic current $\left(U_{\text {depth }}\right)$.

\subsubsection{Isopycnal Slope Spectra and Turbulent Dissipation}

[15] Isopycnal slope spectra were utilized to predict dissipation of TKE $(\varepsilon)$. Isotherm displacements $(\zeta)$ were calculated for several hours following the passage of the bore relaxations (warm fronts) as,

$$
\zeta=z-Z_{o}(\rho)
$$

where $z$ is the thermistor depth and $Z_{o}(\rho)$ is the depth at which the observed density $(\rho)$ is equal to the reference density profile [Klymak and Moum, 2007a, 2007b]. Reference density profiles were taken near the arrival of the warm fronts where the density field did not change significantly in time and spatial resolution was increased by linearly interpolating between adjacent loggers. A Taylor-advection scheme was employed to convert time measurements of $\zeta$ into the spatial domain using

$$
x=c_{o b s} t
$$

[16] Horizontal gradients of $\zeta$ were computed to yield the isopycnal slope $\left(\zeta_{x}\right)$. Time series of $\zeta_{x}$ were then FFTed as outlined above to produce isopycnal slope spectra $\left(\phi_{\zeta_{x}}\right)$. These spectra were lightly smoothed using a 9-point geometric mean filter, which had no significant effect on dissipation estimates.

[17] The turbulence subrange consists of both the inertialconvective and inertial-diffusive subranges,

$$
\phi_{\zeta_{x}}^{T u r b}=4 \pi \frac{\Gamma\langle\varepsilon\rangle}{\left\langle N^{2}\right\rangle}\left[C_{T}\langle\varepsilon\rangle^{-1 / 3}\left(2 \pi k_{x}\right)^{1 / 3}+q \nu^{1 / 2}\langle\varepsilon\rangle^{-1 / 2}\left(2 \pi k_{x}\right)\right],
$$

where $C_{T} \approx 0.44$ and $q \approx 2.3$ are constants, $\left\langle N^{2}\right\rangle$ is the timemean of the average vertical buoyancy frequency squared over the relaxation event with $N^{2}=-\frac{g}{\rho_{o}} \frac{\partial \rho}{\partial z}, k_{x}$ is the horizontal wave number, $\Gamma=0.2$ is the assumed mixing efficiency, $\langle\varepsilon\rangle$ is the average dissipation following the passage of the warm front, and $\nu$ is the kinematic viscosity of seawater [Klymak and Moum, 2007a, 2007b; Woodson et al., 2011]. It is important to note here that $\Gamma=0.2$ was taken to be a constant based on the turbulence activity numbers $\left(\varepsilon / \nu N^{2}\right.$, Section 4.2) found in this study [Shih et al., 2005]. $\langle\varepsilon\rangle$ was estimated by fitting the observed $\phi_{\zeta_{x}}$ to equation (3) in the turbulence subrange $\left(0.04<k_{x}<0.3 \mathrm{cpm}\right)$ and using a nonlinear least squares regression to find $\langle\varepsilon\rangle$ [Woodson et al., 2011]. Confidence limits $(95 \%)$ for $\langle\varepsilon\rangle$ were found by fitting the upper and lower $95 \%$ confidence intervals of $\phi_{\zeta_{x}}$ to equation (3). Sensitivity of the above procedure to $c_{o b s},\left\langle N^{2}\right\rangle$, and $\Gamma$ was estimated by varying the three parameters and looking at the ratio of $\langle\varepsilon\rangle /\left\langle\varepsilon_{o}\right\rangle$ for each parameter, where $\left\langle\varepsilon_{o}\right\rangle$ is the average dissipation calculated from the originally observed parameters.

\section{Results}

\subsection{General Characteristics and Propagation}

[18] A time series of density measured at the $\mathrm{MN}$ mooring during the week-long period (10 to 16 May 2010; Figure 2) clearly shows repeated episodes of energetic cold (bores) and warm (relaxations) water intrusions propagating through the array. The observed bores are non-canonical. The cold water events (bores) take the form of sudden changes in the density field, especially in the bottom portion of the water column, where the waters change quickly from nearly homogeneous to stratified $\left(\Delta T \sim-0.5^{\circ} \mathrm{C}\right.$, cooling, 1 min for $\Delta T$ ). Following the arrival of the initial bore, a series of small amplitude internal waves (10-20 min period) are observed, as the temperature gradually decreases over several hours 

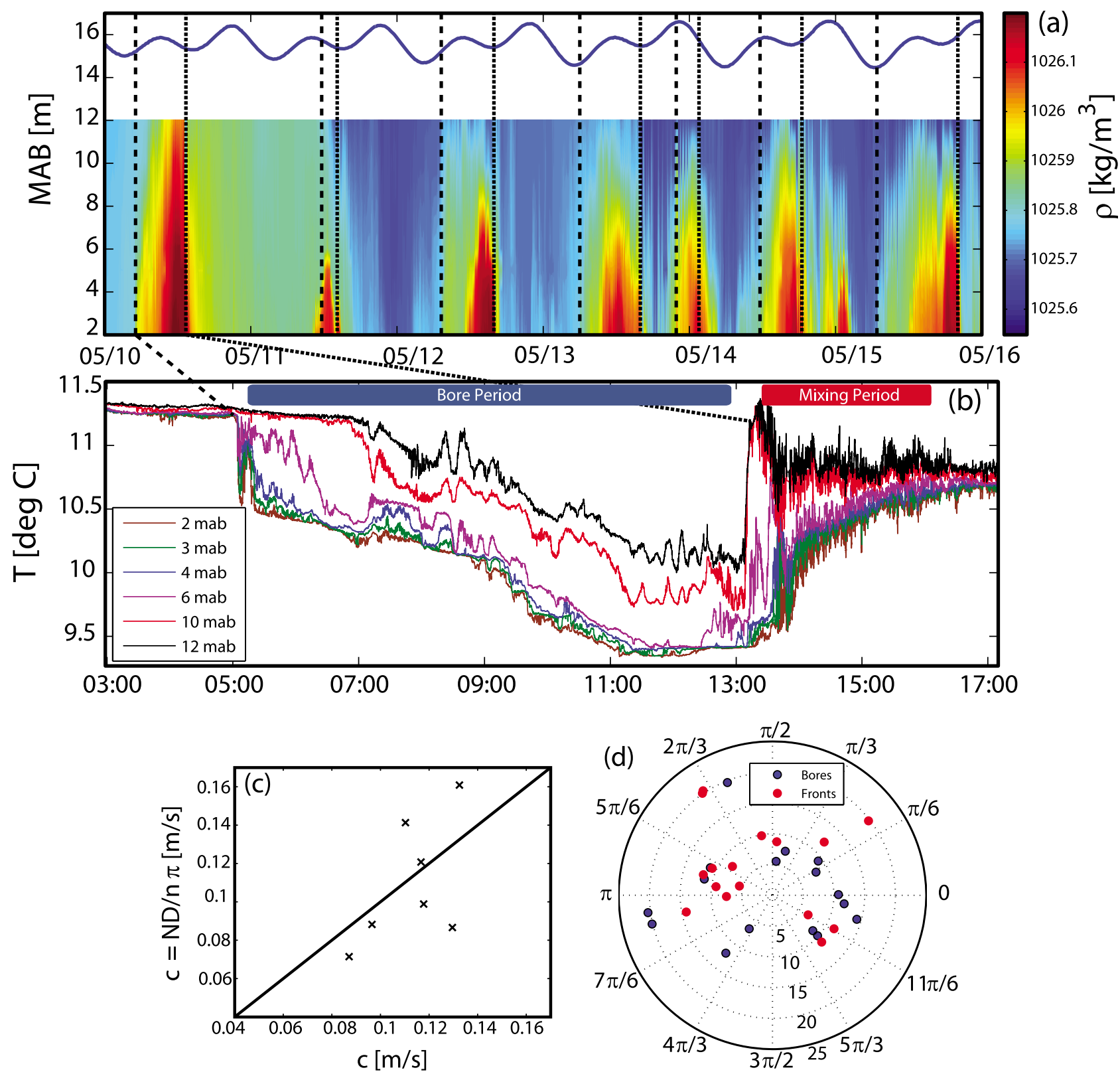

Figure 2. (a) Density contour plot from MN highlighting the arrival of bores and relaxations with dashed black lines and dotted black lines, respectively, along with the location of the free surface. (b) Time series of temperature at various heights throughout the water column for the 10 May 2010 bore and relaxation event. The bore (blue) and mixing (red) periods for this particular event are indentified with boxes. (c) The calculated bore propagation speed against the theoretical phase speed of a mode-one internal wave. (d) Phasing with respect to the lowest low tidal height (see text for details) for the bores (blue) and relaxations (red), respectively, as a function of the time in hours between the initial bore and relaxation $(\Delta \mathrm{t})$.

(from hereafter referred to as the bore period). The water column structure again changes dramatically at the end of the bore period when the waters suddenly warm $\left(\Delta T \geq 1{ }^{\circ} \mathrm{C}\right.$, warming, $5 \mathrm{~min}$ for $\Delta T$ ), a process we refer to as the warm front relaxation since it returns the water column to nearly its original state. Following the sharp front, high-frequency fluctuations ( $<1$ min period) are sustained over several hours and erode the stratification until the water column returns to being well mixed (from hereafter referred to as the mixing period).
[19] The propagation speed of the bores $(c)$ is compared to the theoretical propagation speed of a linear, hydrostatic, first-mode internal wave [e.g., Venayagamoorthy and Fringer, 2007],

$$
c_{1}=\frac{N D}{\pi}
$$

where $D$ is the water depth and $N$ is the maximum of the ten-minute averaged buoyancy frequency following the bore 


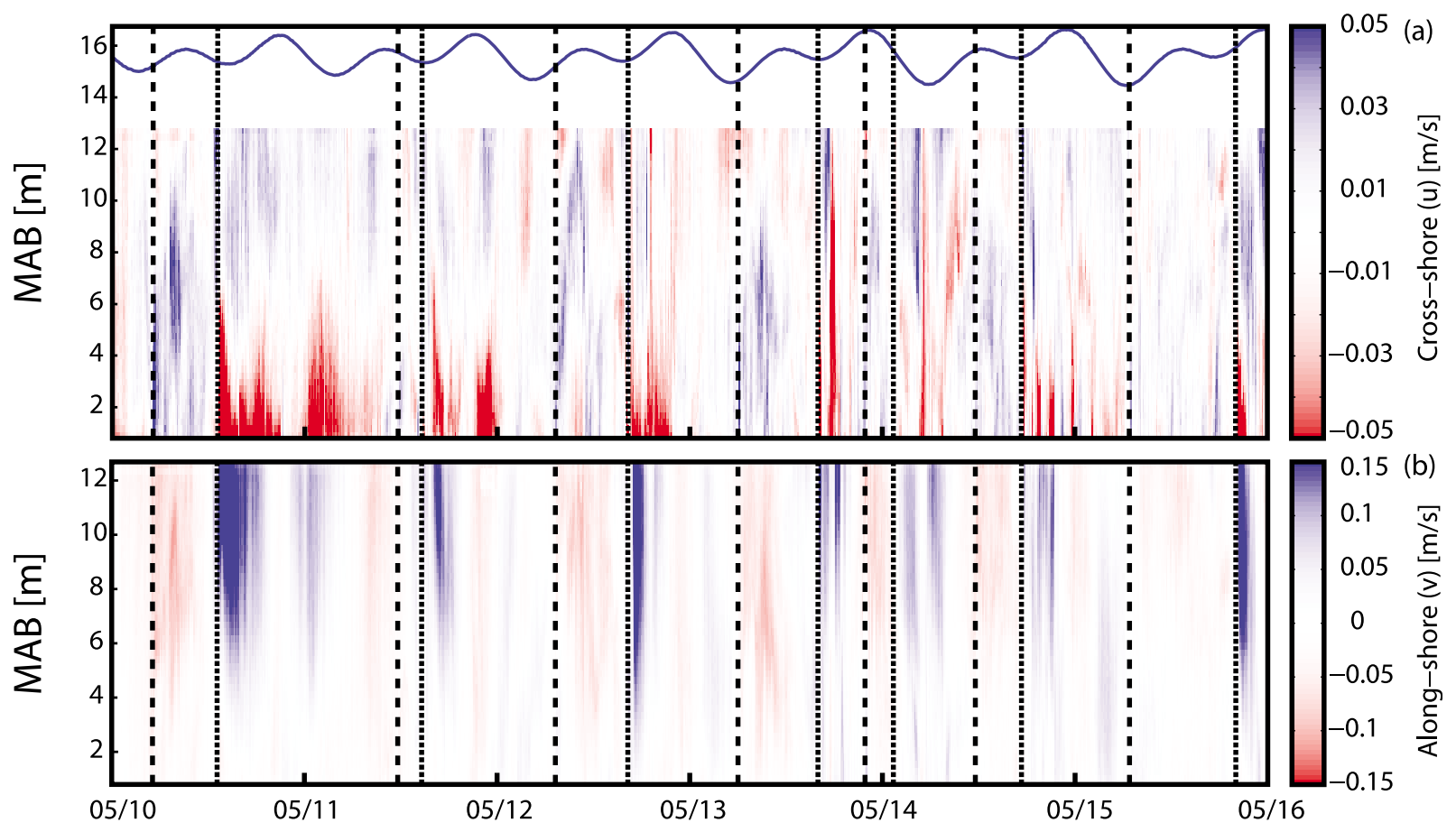

Figure 3. Velocity contour plots from MN for (a) cross-shore and (b) along-shore velocities, highlighting the arrival of bores and relaxations with dashed black lines and dotted black lines, respectively, along with the location of the free surface. Velocities shown are ten-minute averages.

arrival (Figure 2c). Observations deviated slightly from linear theory, likely due to the nonlinear signature of the bores ( Fr 0.7). Phase speeds estimated using both normal mode analysis and solutions to the Taylor-Goldstein equations [Smyth et al., 2011] were extremely erratic due to the rapidly varying density field. The observed median propagation speed of the bores and relaxations (not shown) was 0.12 and $0.16 \mathrm{~m} / \mathrm{s}$, respectively. Directionality of the bores as they passed through the moorings indicates a median heading of $195.4^{\circ}$ (range of $176.2^{\circ}$ to $201.76^{\circ}$ ) from true north, which is inside the bay and appearing to come from near the canyon mouth (Figure 1a). Conversely, the relaxations were modulated by the local along-shore barotropic currents and had a median heading of $153.8^{\circ}$ (range of $136.0^{\circ}$ to $154.3^{\circ}$; Figure 1a), which is roughly along-shelf headed into the bay.

[20] Analysis of the longer time record (1 to 16 May 2010) of densities from the XS mooring was performed to elucidate the timing and arrival of the bores and relaxations with respect to the local tidal phase. Tides in the bay are mixed semi-diurnal and dominated by the $M_{2}$ tidal component (Figure 2a) [e.g., Breaker and Broenkow, 1994]. Tidal phasing was referenced with respect to the lowest lows on 1 May and 10 May 2010 with a diurnal period ( $24.82 \mathrm{~h}$ period). Two reference dates were used because the interaction of the mixed tidal frequencies $\left(M_{2}\right.$ and $\left.K_{1}\right)$ in the transition from neap to spring tide causes a slight phase shift so that the lowest low changes. The time between the bore and relaxation $(\Delta t$ bore period) arrival was also calculated. The phasing with respect to tidal height of the bore and relaxation, respectively, as a function of $\Delta t$ shows no apparent pattern between the timing of arrival with respect to the local tidal phase, as the data is scattered about all phases (Figure 2d).
Likewise, there is a broad range of times between the bore and the relaxation ( $\Delta \mathrm{t} \quad 6-20 \mathrm{~h})$, again with no clear link to the phase of the local tides. Further examination of the record indicates no clear pattern in the arrival of the bores and/or relaxations, or $\Delta t$, with respect to spring-neap variability of the tide (not shown). These results are expected given that the observed propagation speeds may have been comparable to spatially and temporally ambient currents throughout the bay. Two additional processes may potentially modulate both the timing and duration of the bore-relaxation events. First, regional scale upwelling acts to uplift the thermocline to depths that may allow for observation of these events in the nearshore. Second, internal seiching within Monterey Bay may also contribute to variability of bore-relaxation events on time scales of 5-10 days.

[21] The importance of the bore and relaxation events to the overall local velocity field is shown in Figure 3. While depth-averaged currents are structured in a way that resembles a boundary layer profile, empirical orthogonal function (EOF) analysis (not shown) suggests that this flow is much more sheared than would be predicted given the local sandy bottom, even accounting for the effects of surface waves. The along-shore flow is consistently directed out of the bay and to the northwest with the arrival of the cold bores, switching to positive and into the bay with the arrival of the warm front. Cross-shore velocities, which reach more than $0.1 \mathrm{~m} / \mathrm{s}$ in some places, are much more irregular. However, the arrival of the bores tends to coincide with positive onshore velocities, especially near the bottom of the water column, while the fronts correspond to offshore velocities near the bottom. As with the temperature field, the dominant variability of the velocity field is largely due to the repeated sequence of bores and fronts. 


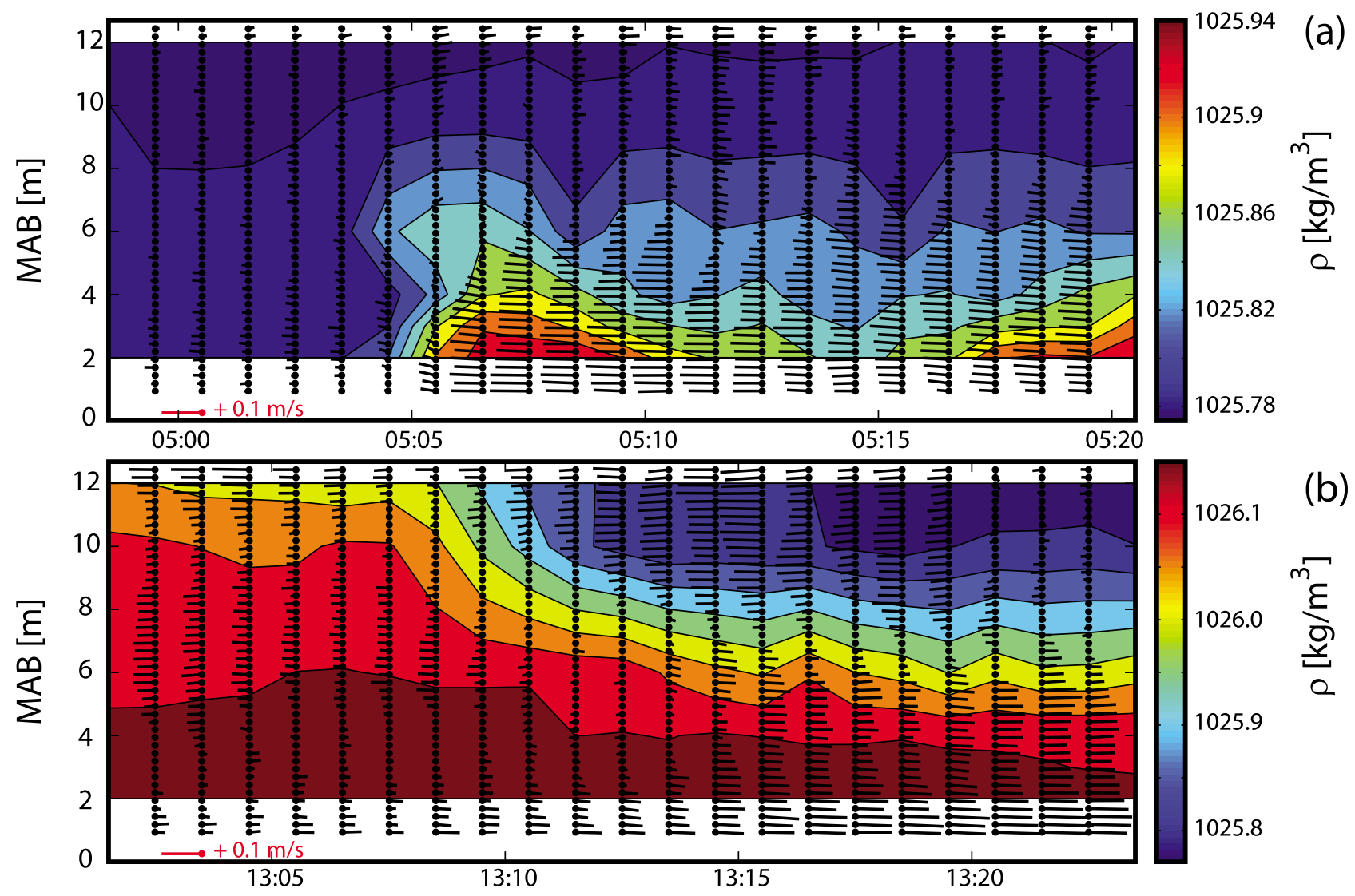

Figure 4. Cross-shore/vertical plane showing velocity vectors superimposed on a contour plot of density at MN on 10 May 2010, illustrating the detailed structure of an individual (a) bore and (b) relaxation event. Densities and velocities shown are one-minute averages, and velocities are depicted in $0.25 \mathrm{~m}$ bins with the tail of the velocity vector denoted by a black circle. The red velocity vector in the bottom left corner is shown for scale and represents a positive cross-shore velocity of $0.1 \mathrm{~m} / \mathrm{s}$.

[22] The detailed velocity and density structure for an example bore and relaxation is shown in Figure 4. Waters are well mixed and quiescent until the arrival of the bore, which is marked by a sharp front of dense water in the form of a gravity current with cross-shelf velocities increasing rapidly to nearly $0.1 \mathrm{~m} / \mathrm{s}$ onshore. The bore is highly nonlinear $(\mathrm{Fr} \sim$ $0.7)$ and unstable at the nose with $\mathrm{O}(1 \mathrm{~m})$ density overturns present. The warm front relaxation takes the form of a surface gravity current with stronger local shear.

\subsection{Bore Versus Mixing Period}

[23] In order to compare energetics and dynamics between the bores and warm front relaxations, composite $(n=7$ events) bore and mixing periods (defined in 3.1) were calculated.

[24] Composite temperature spectra were computed by taking each bore or mixing period event, respectively, linearly detrending, removing the mean, windowing, calculating the spectra, and then averaging all respective events $(n=7)$ in frequency space. The composite mixing period dominated temperature variance at high frequencies by nearly a decade compared to the bore period and the entire record (Figure 5). Likewise, significant energy in the temperature fluctuations during the mixing period was sustained at frequencies higher than the average buoyancy frequency $(\omega>\bar{N})$, indicating that

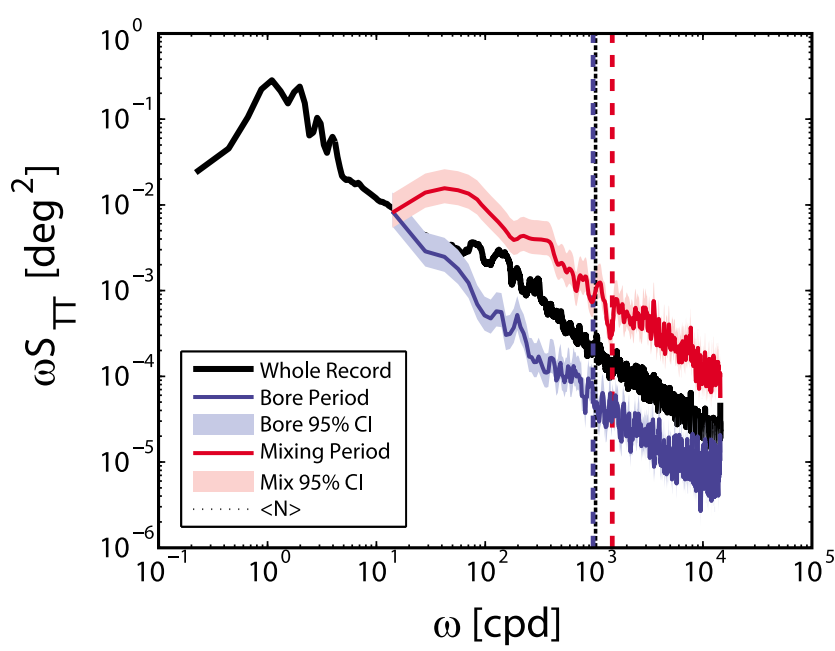

Figure 5. Variance preserving temperature spectra at 2 mab for the entire record (black), as well as composite bore (blue) and mixing (red) periods ( $\mathrm{n}=7$ events). Also shown is the average buoyancy frequency over each respective period. 


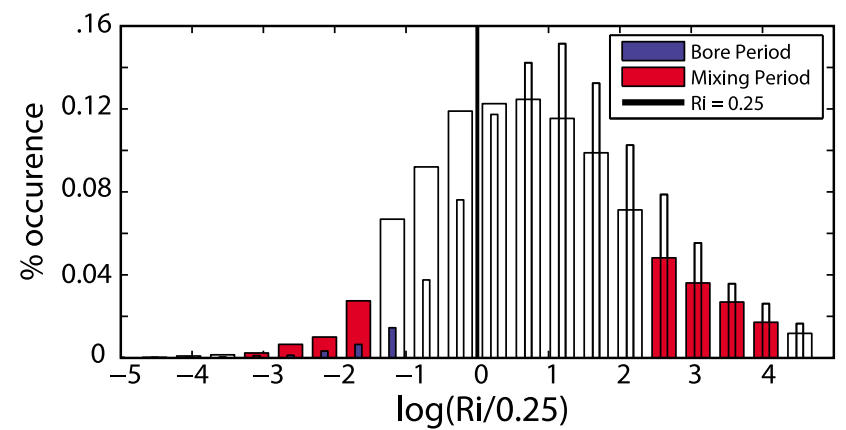

Figure 6. Histograms of normalized, logarithmic gradient Richardson number $[\log (R i / 0.25)<0$ is equivalent to $R i<$ 0.25 ] for composite bore (blue) and mixing (red) periods ( $\mathrm{n}=7$ events), respectively. The solid black line indicates the critical $R i=0.25$.

the variability is not due to internal waves, and is likely due to turbulent fluctuations.

[25] To evaluate the potential for mixing due to shear instabilities, gradient Richardson numbers were calculated as, $R i=\frac{N^{2}}{S^{2}}$, where $S^{2}=\left(\frac{\partial U}{\partial z}\right)^{2}+\left(\frac{\partial V}{\partial z}\right)^{2}$ is the vertical shear in the horizontal direction squared and $(\mathrm{U}, \mathrm{V})$ are ten-minute averaged velocity profiles. While the bores tend to stably stratify the water column $(R i>0.25)$, the relaxation events have a much greater percentage of periods where dynamic instabilities $(R i<0.25)$ may be present (Figure 6). Thus, local shear-generated turbulence during the warm front relaxations (mixing period) contributes significantly to the local temperature variance and provides a mechanism for active mixing of the stratified water column.

\subsection{Turbulent Dissipation and Mixing}

[26] The importance of relaxation events to local mixing was examined by estimating the dissipation rate of TKE using isopycnal slope spectra over the mixing period. Estimates were made near the thermocline ( $6 \mathrm{mab}$ ), although other locations in the stratified interior provided similar results. An example of this result is shown in Figure 7. The low wave number portion of the spectrum $\left(k_{x} \leq 10^{-2} \mathrm{cpm}\right)$ represents the internal wave subrange and depends highly on the stratification and frequency content of the internal wavefield [Klymak and Moum, 2007a, 2007b]. As the spectrum moves toward higher wave numbers, the spectrum turns blue, with increasing energy at higher frequencies. In the turbulence subrange $\left(0.04<k_{x}<0.3 \mathrm{cpm}\right)$, the dissipation fit to equation (3) follows the calculated spectrum. At the highest wave numbers, the spectrum begins to turn red, with decreasing energy at higher frequencies. The reddening of the spectra typically occurred near one standard deviation less than the mean buoyancy wave number,

$$
k_{N}=\frac{2 \pi\langle N\rangle}{c_{o b s}},
$$

likely due to the fact that sharper density gradients and overturns are not resolved by the average buoyancy frequency. For the example shown (Figure 7), the average dissipation over the mixing period $(\langle\varepsilon\rangle)$ was estimated to be $1.41 \times 10^{-8} \mathrm{~m}^{2} / \mathrm{s}^{3}$ with upper and lower error bounds $(95 \%$ confidence intervals) of $2.58 \times 10^{-8}$ and $8.55 \times 10^{-9} \mathrm{~m}^{2} / \mathrm{s}^{3}$, respectively. The range of $\langle\varepsilon\rangle$ values observed over all mixing periods associated with the relaxation of the bores $(\mathrm{n}=7)$ was $2.91 \times 10^{-9}$ to $2.06 \times 10^{-8} \mathrm{~m}^{2} / \mathrm{s}^{3}$, with a mean value of $1.00 \times 10^{-8} \mathrm{~m}^{2} / \mathrm{s}^{3}$. Error bounds for each individual event had similar upper and lower percentage errors as the example given above. A robust feature of the spectra is that for increasing turbulent dissipation, there is an increase in the variance at higher wave numbers, which is consistent with previous studies [Klymak and Moum, 2007a, 2007b].

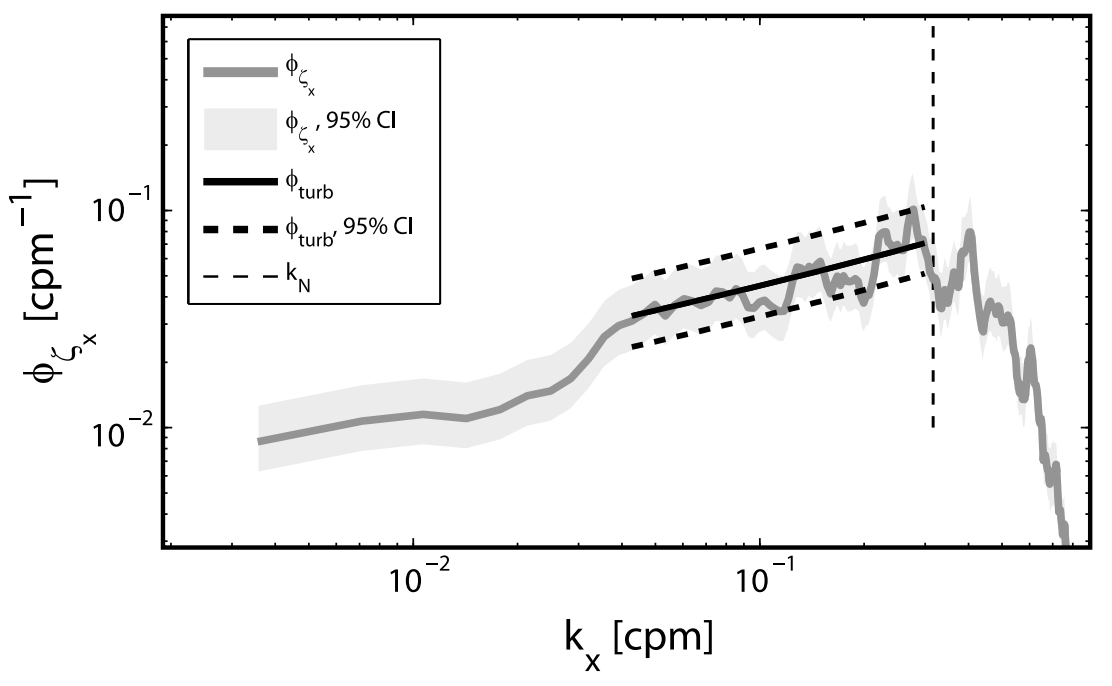

Figure 7. Example isopycnal slope spectrum (dark gray line) for several hours following the relaxation event on 15 May 2010. Confidence intervals (95\%) for the spectrum are denoted by light gray shading, a solid black line indicates the nonlinear least squares regression fit to equation (5) in the turbulence subrange for estimating turbulent dissipation along with upper and lower bounds for dissipation (thick dashed black lines), and the thin dashed black line highlights one standard deviation below the mean buoyancy frequency wave number where the spectrum begins to roll-off. 


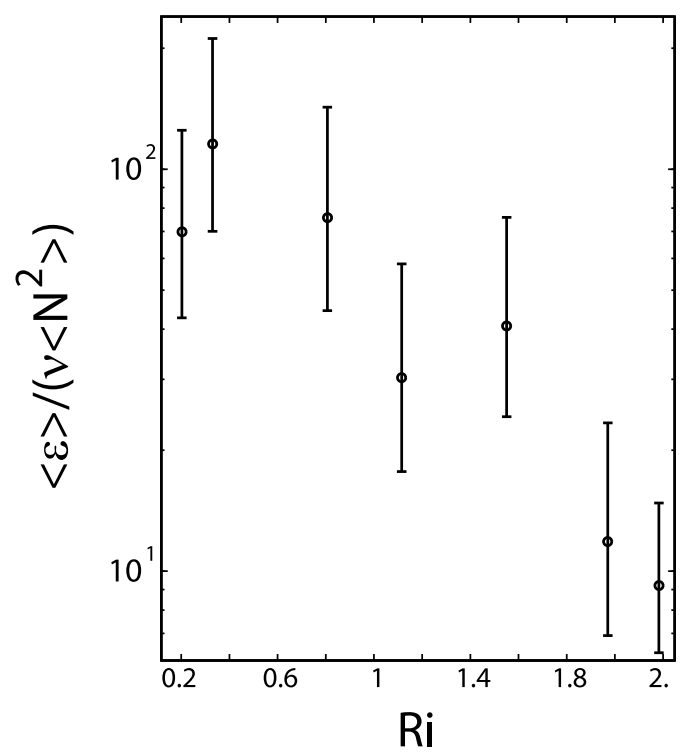

Figure 8. Turbulence activity number $\left(\langle\varepsilon\rangle / \nu\left\langle N^{2}\right\rangle\right)$ as a function of the local gradient Richardson number $(R i)$ for the relaxation events. Richardson numbers presented are the median of the ten-minute averaged values for thirty minutes following the arrival of the warm-front relaxation.

[27] A common measure for characterizing turbulence in stratified environments is the turbulence activity parameter, $\varepsilon / \nu N^{2}$ [e.g., Shih et al., 2005]. In order to evaluate the potential for turbulent mixing due to shear instabilities by relaxation events, the turbulence activity parameter for each mixing period (e.g., $\langle\varepsilon\rangle / \nu\left\langle N^{2}\right\rangle$ ) was plotted as a function of the local median gradient $R i$ following the warm fronts (Figure 8). An inverse relationship exists between the turbulence activity parameter and local median $R i$ such that at the highest activity numbers, the local median $R i$ nears the critical value (0.25). Furthermore, plotting the turbulence activity against the number of individual points that had $R i<$ 0.25 following the relaxations revealed the general trend that as the turbulence activity increased, so did the number of potentially dynamically unstable events (i.e., $R i<0.25$, figure not shown). This again points to local shear-produced turbulence as the dominant mixing mechanism in the stratified interior at this site.

[28] Uncertainty of the dissipation estimates was evaluated by performing a sensitivity analysis with three input parameters to the isopycnal slope spectra model: $c_{o b s},\left\langle N^{2}\right\rangle$, and $\Gamma$. The observed propagation speed $\left(c_{o b s}\right)$ and averaged buoyancy frequency $\left(\left\langle N^{2}\right\rangle\right)$ were varied from 75 to $125 \%$ of the originally calculated value, while the mixing efficiency $(\Gamma)$ was varied between 0.1 and 0.29 based on direct numerical simulations (DNS) and turbulence activity numbers observed since $\Gamma$ itself is a function of the turbulence activity number [Shih et al., 2005]. Figure 9 displays the effects of the three inputs to the calculated dissipation along with standard deviations across all relaxation events $(n=7)$ at each point. Dissipation estimates were not sensitive to the calculated values of $c_{o b s}$ and $\left\langle N^{2}\right\rangle$, as these parameters never changed the calculated dissipation by more than a factor of two, which is within the $95 \%$ confidence range. Likewise, dissipation was weakly dependent on the choice of mixing efficiency near 0.2 , but did change by a factor of three at the smallest value of $\Gamma=0.1$; however, given the observed turbulence activity numbers, $\Gamma$ is not likely to be this low [Shih et al., 2005] and hence not as influential in the dissipation estimate. The only parameter that showed significant variability across different relaxation events, as highlighted by the standard deviations shown in Figure 9, was $c_{o b s}$. These results highlight the robustness of the isopycnal slope spectra model for estimating dissipation.

\section{Discussion}

\subsection{Non-canonical Nature}

[29] Using a numerical model, we examined the noncanonical nature of the observed bores, in which the initial bore is followed by gradual cooling of the water column until an abrupt warm front relaxation and high frequency oscillations quickly erode the stratification. This structure appears
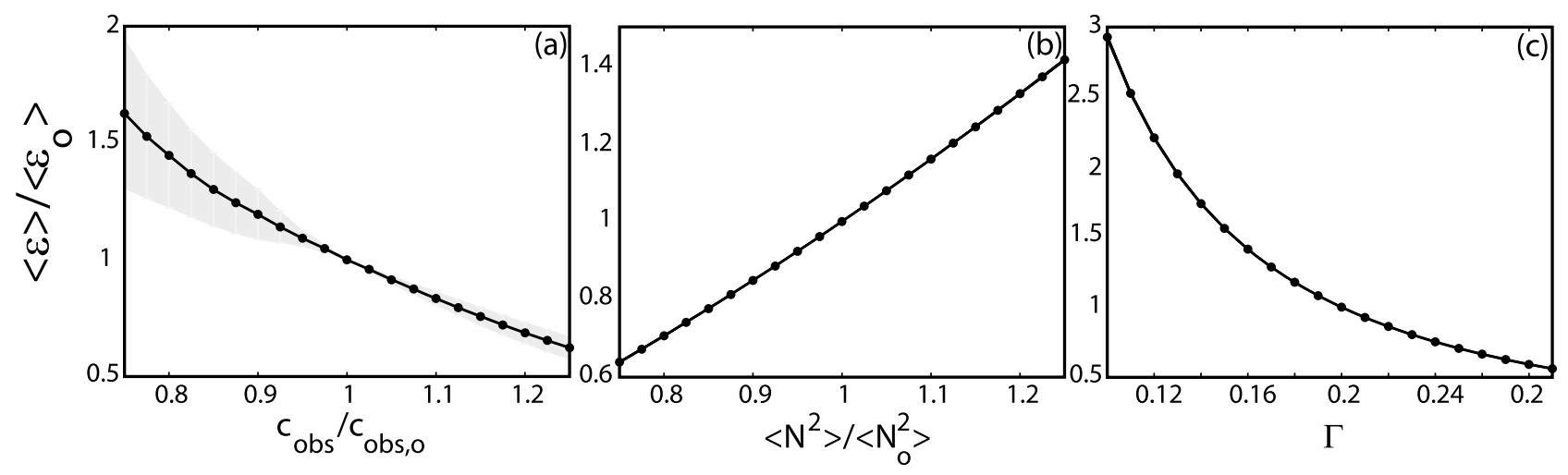

Figure 9. Sensitivity of the calculated dissipation rates to three input parameters to the isopycnal slope spectra model: (a) the observed relaxation propagation speed $\left(c_{o b s}\right),(\mathrm{b})$ the calculated average stratification over the mixing period $\left(\left\langle N^{2}\right\rangle\right)$, and (c) the mixing efficiency $(\Gamma)$. A subscript " $o$ " denotes the originally calculated and/or observed value. Black dots represent the mean value taken across all $(n=7)$ relaxation events, while gray shading indicates one standard deviation from the mean. Note that for Figures $9 \mathrm{~b}$ and $9 \mathrm{c}$ the standard deviation is very small so that shading is difficult to distinguish. 

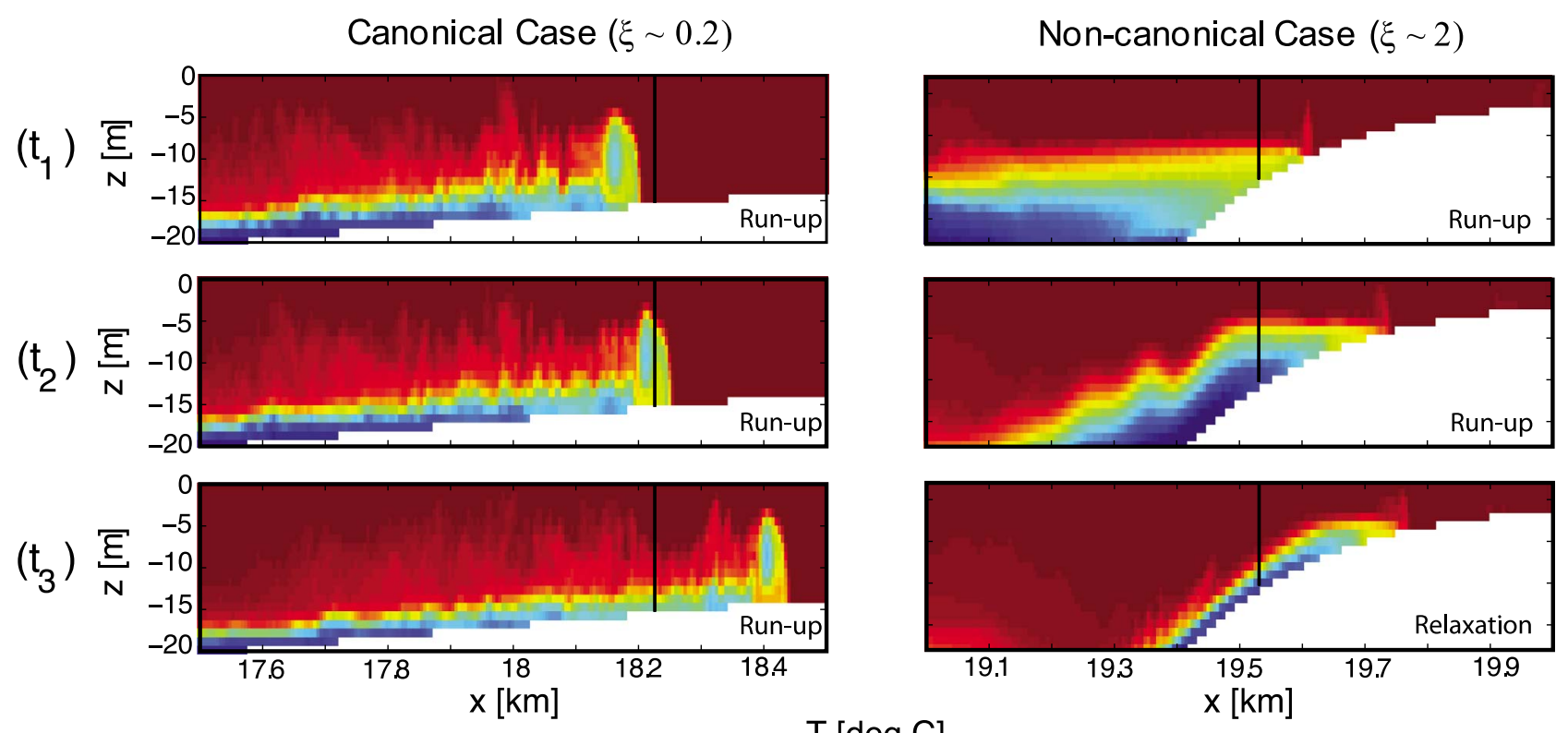

$\mathrm{T}[\operatorname{deg} \mathrm{C}]$
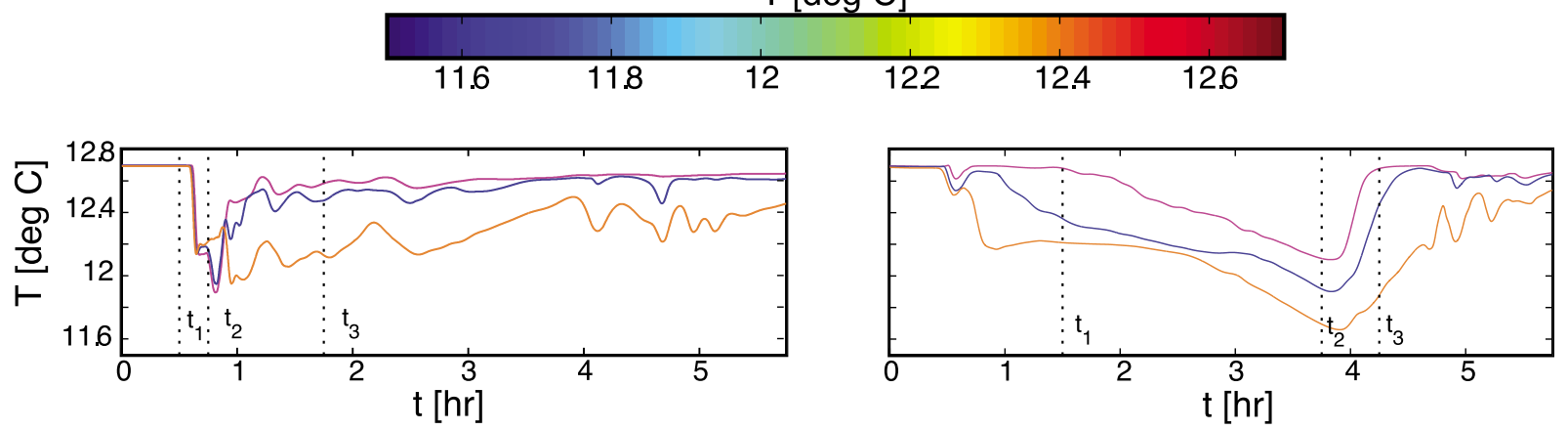

Figure 10. Numerical model results for the canonical (gentle slope, $\xi \quad 0.2$ ) and non-canonical (actual slope, $\xi \quad 2)$ cases. Shown in the top three rows are cross-shelf/vertical snapshots of the bores at different representative times $\left(t_{1}, t_{2}\right.$, and $\left.t_{3}\right)$. The $15 \mathrm{~m}$ isobath is labeled with a vertical black line. The bottom row shows the vertical temperature structure at the $15 \mathrm{~m}$ isobath, including the $2 \mathrm{mab}$ (brown), $4 \mathrm{mab}$ (blue), and $6 \mathrm{mab}$ (magenta), virtual thermistors, similar to Figure 2b. Also shown on the bottom row with dotted black lines are the corresponding snapshot times $\left(t_{1}, t_{2}\right.$, and $\left.t_{3}\right)$ from the top three rows. Time in the bottom row is referenced to the beginning of representative bore events in each simulation.

to be dependent on the bathymetric slope, which can be measured relative to the internal wave slope using the internal Iribarren number,

$$
\xi=\frac{s}{\left(\frac{a}{\lambda}\right)^{1 / 2}},
$$

where $s$ is the bathymetric slope, and $a$ and $\lambda$ are the offshore amplitude and wavelength of the incoming internal wave, respectively [e.g., Boegman et al., 2005]. To examine this dependence, we employed the fully nonlinear, nonhydrostatic model SUNTANS [Fringer et al., 2006] in a twodimensional domain that represents a vertical transect along the median observed propagation path of the bores $\left(195.4^{\circ}\right.$; Figures 1a and 1c). The model domain was $20 \mathrm{~km}$ long and $80 \mathrm{~m}$ deep, with a horizontal grid spacing $(\Delta x)$ of $5 \mathrm{~m}$ and a vertical grid spacing $(\Delta z)$ of $1 \mathrm{~m}$. A time step size $(\Delta t)$ of $1 \mathrm{~s}$ was chosen in order to satisfy the stability constraint associated with the calculation of the internal waves. The turbulence model assumed a constant eddy viscosity of $10^{-4} \mathrm{~m}^{2} / \mathrm{s}$ in both the horizontal and vertical directions and no scalar diffusivity. The model was initialized with realistic stratification measured from CTD casts in southern Monterey Bay near the time of the field observations (courtesy of Monterey Bay Research Aquarium Institute), and was forced at the offshore boundary by the mode- 1 internal wavefield associated with this stratification and the $M_{2}$ tidal frequency. The model was run for six tidal periods ( $2.7 \times 10^{5}$ time steps). With these parameters, two scenarios were considered: a canonical case with a gentler slope $\left(\begin{array}{ll}\xi & 0.2\end{array}\right)$ and a noncanonical case with a steep slope taken from actual bathym-

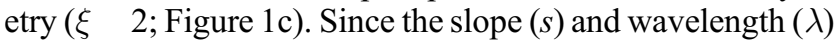
are set by the bathymetry and forcing, respectively, the modeled Iribarren number $(\xi)$ is set by the initial amplitude (a) of the wave, which was chosen to match the observed change in temperature due to the bores in the realistic case.

[30] The model results show a clear distinction in the nature of the bores for different Iribarren numbers. Figure 10 shows, for both cases, a snapshot of the bore at several times, along with the temperature signal observed at the $15 \mathrm{~m}$ isobath (the location of field observations at $\mathrm{MN}$ ). The lower Iribarren number (gentler slope) case results in a canonical 


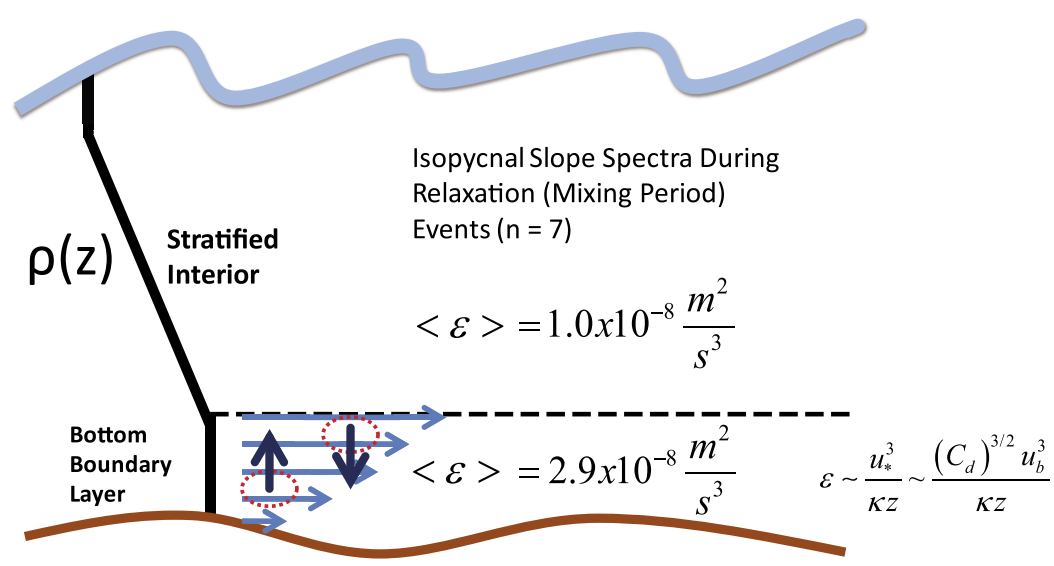

Figure 11. Turbulence conceptual model for the stratified interior during bore events in southern Monterey Bay. Local shear-produced TKE in the stratified interior by the warm front relaxations, rather than the bottom-generated TKE, dominates mixing in the middle of the water column. Dissipation in the stratified interior calculated using isopycnal slope spectra and bottom-generated turbulence estimated using the law of the wall and a drag law near the bed.

bore structure. In this case, the incoming wave has time to shoal, steepen, and break, sending a bore (bolus) up the slope. This leads to a more canonical temperature signal at the $15 \mathrm{~m}$ isobath with an abrupt cold front followed by gradual warming [e.g., Leichter et al., 1996; Hosegood and van Haren, 2004]. Conversely, the higher Iribarren number (steeper slope) case results in a non-canonical bore structure that is qualitatively similar to our observations. In this case, the incoming wave does not have time to shoal or break. Rather, the wave essentially sloshes up and down the steep slope in a similar manner to a standing wave at a vertical wall. As the wave sloshes up, it sends gradually cooler water past the $15 \mathrm{~m}$ isobath. After reaching its peak position on the slope, it quickly recedes back down the slope, resulting in an abrupt warm front at the $15 \mathrm{~m}$ isobath. The corresponding temperature signal (Figure 10) is qualitatively similar to that shown in Figure 2b. Although the model greatly simplifies the real system, it captures and reproduces the basic dynamics of the observed non-canonical bores, and demonstrates the importance of the Iribarren number on internal wave shoaling dynamics in southern Monterey Bay and potentially other nearshore regions.

\subsection{Turbulent Dissipation and Mixing}

[31] Estimates of turbulent dissipation rates in coastal zones are important in determining vertical mixing of tracers. Variability in turbulent mixing on the shelf has been attributed to various physical phenomena and often spans several orders of magnitude [Carter et al., 2005]. Conventional estimates of turbulent dissipation with moored instruments have significant issues in coastal zones due to small velocities with a high noise floor and wave contamination. Likewise, wave-turbulence separation methods for estimating turbulent stresses and shear production (and ultimately dissipation assuming equilibrium turbulence) from ADCPs are also affected by waves [e.g., Rosman et al., 2008; Kirincich et al., 2010], with wave-turbulence separation methods often not appropriate in certain environments [Walter et al., 2011]. However, the technique of using isopycnal slope spectra to estimate dissipation rates does not suffer significantly from surface wave contamination and may be appropriate for use in coastal waters with strong wave signatures [e.g., Woodson et al., 2011].

[32] Turbulent dissipation rates of the warm front relaxations in this study were on average an order of magnitude larger than the average dissipation rates found by Carter et al. [2005] on the southern shelf of Monterey Bay using microstructure measurements. Likewise, Carter et al. [2005] observed the passing of high acoustic backscatter events with elevated dissipation rates the same order of magnitude as the events in this study, which they attribute to nonlinear internal waves. However, they lacked the spatial and temporal resolution to fully resolve these events that are likely similar to the bores observed in this study. Given that their average dissipation rates included these elevated dissipation events, it is not a leap to say that the bore events in this study might be associated with dissipation rates two orders of magnitude larger than the background level (i.e., excluding bore events) previously observed on the southern shelf of Monterey Bay.

[33] Dissipation estimates can be compared to the nearbed, bottom-generated turbulence by considering the law of the wall scaling for dissipation,

$$
\varepsilon \frac{u_{*}^{3}}{\kappa z},
$$

where $\kappa=0.41$ is the Von Kármán constant, $z$ is the height above the bed, and $u_{*}$ is the friction velocity [Pope, 2000]. The friction velocity squared is estimated using a drag-law near the bed,

$$
u_{*}^{2}=C_{d} u_{b}^{2},
$$

where $C_{d}=2.5 \times 10^{-3}$ is the drag coefficient for a sandy bottom [Gross and Nowell, 1983], and $u_{b}=\sqrt{u^{2}+v^{2}}$ is the near-bed velocity taken to be at the first ADCP bin height of $z=0.935 \mathrm{~m}$. Thus, the bottom-generated turbulence can be approximated by,

$$
\varepsilon \quad \frac{\left(C_{d}\right)^{3 / 2} u_{b}^{3}}{\kappa z} .
$$


[34] The mean near-bed dissipation was $2.90 \times 10^{-8} \mathrm{~m}^{2} / \mathrm{s}^{3}$, which is comparable to the mean dissipation value near the thermocline of $1.00 \times 10^{-8} \mathrm{~m}^{2} / \mathrm{s}^{3}$ found using isopycnal slope spectra. Turbulence in the stratified interior during the relaxation events is the same order of magnitude as the nearbed, bottom-generated turbulence. Moreover, the stratification present throughout the bore/relaxation event should limit bottom-generated TKE to the region near the bed where it is unable to penetrate vertically [cf. Monismith and Fong, 1996]. Consequently, the local shear-produced TKE in the stratified interior by the warm front relaxations, rather than the bottom-generated TKE, dominates mixing in the middle of the water column. It appears that the turbulence structure in the presence of nearshore bores is substantially different than would be expected from the standard conceptual model of a bottom mixed layer under a stratified interior (Figure 11).

[35] Vertical turbulent diffusivities were quantified during the relaxation events following the Osborn [1980] formulation:

$$
\kappa_{\rho}=\Gamma \frac{\langle\varepsilon\rangle}{\left\langle N^{2}\right\rangle}
$$

where $\Gamma=0.2$ was taken to be a constant based on the turbulence activity numbers found in this study and the DNS simulations of Shih et al. [2005]. Diffusivities ranged from $1.84 \times 10^{-6}$ to $2.31 \times 10^{-5} \mathrm{~m}^{2} / \mathrm{s}$ with a mean value of $1.00 \times 10^{-5} \mathrm{~m}^{2} / \mathrm{s}$, indicating the importance of the bore relaxation events to diapycnal mixing in the interior.

\section{Summary and Implications}

[36] We observed transient stratification and mixing events associated with nearshore internal bores in southern Monterey Bay using an array of instruments with high spatial and temporal resolution. Velocity and density data show repeated episodes of cold and warm water intrusions propagating through the array. The arrival of the bores is characterized by surging masses of dense (cold) water near the bottom that tend to stratify the water column. The bore is followed by a gradual decline in temperature throughout the water column (bore period) until a sharp warm-front relaxation and high frequency fluctuations return the column back to roughly its original state (mixing period). The structure of the bores did not follow the canonical shape of shoaling internal waves on a gentle, linear slope. The non-canonical nature of these bores and relaxations was examined with a numerical model and explained by a dependence on the internal Iribarren number.

[37] Composite bore and mixing periods ( $n=7$ events) revealed increased temperature variance at high frequencies during the mixing period $(\omega>\bar{N})$, as well as a greater percentage of events where dynamic instabilities may be present $(R i<0.25)$. Estimates of turbulent dissipation rates in the stratified interior during the mixing period were found using isopycnal slope spectra and revealed average values the same order of magnitude as near-bed bottom-generated turbulence. Observations indicate that local shear-produced TKE by the warm front relaxations in the stratified interior dominates mixing in the middle of the water column.

[38] The transient stratification and mixing events generated by these bores dramatically alter the physical environment found in the nearshore and represent the dominant source of variability in this ecologically important region of the inner shelf. The bores and fronts are an important mechanism by which deeper offshore waters are supplied to the nearshore. These waters are also a significant source of nutrients to support macrophyte and phytoplankton growth [Leichter et al., 1996; McPhee-Shaw et al., 2007; Lucas et al., 2011], and can significantly affect other organisms because of the low dissolved oxygen (DO) concentration and $\mathrm{pH}$ that is found at depth in the eastern Pacific [e.g., Checkley and Barth, 2009]. The low DO waters can also lead to the development of hypoxic events [Chan et al., 2008], if the relaxation events do not provide enough mixing to reoxygenate the water column. Likewise, the bores and relaxations are thought to promote the exchange of organisms and larvae between the nearshore and regions of the inner shelf further offshore [e.g., Pineda, 1991, 1994, 1995, 1999]. While large-scale models like the Central California Coast Regional Ocean Modeling System (ROMS) have significantly improved our understanding of how mesoscale transport might affect connectivity of different habitats, they cannot yet be used with much confidence to assess connectivity with nearshore environments like kelp forests because these current models simply do not resolve important physics such as internal bores. Finally, the turbulence in the presence of nearshore internal bores is substantially different than would be expected from the standard conceptual model of a bottom mixed layer under stratified interior. This ultimately affects the diapycnal mixing that is critical for many ecological processes including benthic grazing, primary production, nutrient cycling, hypoxia development, and the mixing of tracers such as pollutants from sewage outfalls [e.g., Wolanski and Pickard, 1983; Leichter et al., 1996; Boehm et al., 2002; Chan et al., 2008]. As the results of this study show, internal bores dramatically alter the physics of coastal environments and need to be considered when assessing nearshore water column dynamics and local mixing.

[39] Acknowledgments. R. Walter was supported by the Department of Defense (DoD) through the National Defense Science and Engineering Graduate Fellowship (NDSEG) Program. Additional support to R. Walter and R. Arthur was provided by the Stanford Graduate Fellowship (SGF). Support to C. Woodson was provided by the Center for Ocean Solutions. R. Arthur and O. Fringer gratefully acknowledge ONR grant N00014-081-0904 (scientific officers Dr. C. Linwood Vincent, Dr. Terri Paluszkiewicz and Dr. Scott Harper). The helpful comments of two anonymous reviewers contributed significantly to this manuscript. Special thanks to the students of the Spring 2010 course taught at Stanford University, CEE 363G Field Techniques in Coastal Oceanography, who helped with the deployment and recovery of the instruments. We acknowledge Bill Smyth for providing code for solving the Taylor-Goldstein equations. Bathymetry data used in this study were acquired, processed, archived, and distributed by the Seafloor Mapping Lab of California State University Monterey Bay.

\section{References}

Boegman, L., G. N. Ivey, and J. Imberger (2005), The degeneration of internal waves in lakes with sloping topography, Limnol. Oceanogr., 50, 1620-1637, doi:10.4319/10.2005.50.5.1620.

Boehm, A. B., B. F. Sanders, and C. D. Winant (2002), Cross-shelf transport at Huntington Beach. Implications for the fate of sewage discharged through an offshore ocean outfall, Environ. Sci. Technol., 36, 1899-1906, doi:10.1021/es0111986.

Breaker, L. C., and W. W. Broenkow (1994), The circulation of Monterey Bay and related processes, Oceanogr. Mar. Biol., 32, 1-64.

Carter, G. S. (2010), Barotropic and baroclinic $\mathrm{M}_{2}$ tides in the Monterey Bay region, J. Phys. Oceanogr., 40, 1766-1783, doi:10.1175/ 2010JPO4274.1. 
Carter, G. S., M. C. Gregg, and R. Lien (2005), Internal waves, solitary-like waves, and mixing on the Monterey Bay shelf, Cont. Shelf Res., 25 1499-1520, doi:10.1016/j.csr.2005.04.011.

Chan, F., J. A. Barth, J. Lubchenco, A. Kirincich, H. Weeks, W. T. Peterson, and B. A. Menge (2008), Emergence of anoxia in the California Current large marine ecosystem, Science, 319, 920, doi:10.1126/ science. 1149016.

Checkley, D. M., Jr., and J. A. Barth (2009), Patterns and processes in the California Current System, Prog. Oceanogr., 83, 49-64, doi:10.1016/ j.pocean.2009.07.028.

Colosi, J. A., R. C. Beardsley, J. F. Lynch, G. Gawarkiewicz, C. Chiu, and A. Scotti (2001), Observations of nonlinear internal waves on the outer New England continental shelf during the summer Shelfbreak Primer study, J. Geophys. Res., 106, 9587-9601, doi:10.1029/2000JC900124.

Davis, K. A., and S. G. Monismith (2011), The modification of bottom boundary layer turbulence and mixing by internal waves shoaling on a barrier reef, J. Phys. Oceanogr., 41, 2223-2241, doi:10.1175/ 2011JPO4344.1.

Emery, W. J., and R. E. Thomson (2004), Data Analysis Methods in Physical Oceanography, 2nd ed., 638 pp., Elsevier, Amsterdam.

Fringer, O. B., M. Gerritsen, and R. L. Street (2006), An unstructured-grid, finite-volume, nonhydrostatic, parallel coastal ocean simulator, Ocean Modell., 14, 139-173, doi:10.1016/j.ocemod.2006.03.006.

Grimshaw, R., E. Pelinovsky, and T. Talipova (1999), Solitary wave transformation in a medium with sign-variable quadratic nonlinearity and cubic nonlinearity, Physica D, 132, 40-62, doi:10.1016/S0167-2789 (99)00045-7.

Gross, T. F., and A. R. M. Nowell (1983), Mean flow and turbulence scaling in a tidal boundary layer, Cont. Shelf Res., 2, 109-126, doi:10.1016/ 0278-4343(83)90011-0.

Hosegood, P., and H. van Haren (2004), Near-bed solibores over the continental slope in the Faeroe-Shetland Channel, Deep Sea Res., Part II, 51, 2943-2971, doi:10.1016/j.dsr2.2004.09.016.

Kirincich, A. R., S. J. Lentz, and G. P. Gerbi (2010), Calculating Reynolds stresses from ADCP measurements in the presence of surface gravity waves using the cospectra-fit method, J. Atmos. Oceanic Technol., 27, 889-907, doi:10.1175/2009JTECHO682.1.

Klymak, J. M., and J. N. Moum (2003), Internal solitary waves of elevation advancing on a shoaling shelf, Geophys. Res. Lett., 30(20), 2045, doi:10.1029/2003GL017706.

Klymak, J. M., and J. N. Moum (2007a), Oceanic isopycnal slope spectra. Part I: Internal waves, J. Phys. Oceanogr., 37, 1215-1231, doi:10.1175/ JPO3073.1.

Klymak, J. M., and J. N. Moum (2007b), Oceanic isopycnal slope spectra. Part II: Turbulence, J. Phys. Oceanogr., 37, 1232-1245, doi:10.1175/ JPO3074.1.

Kunze, E., L. K. Rosenfeld, G. S. Carter, and M. C. Gregg (2002), Internal waves in Monterey Submarine Canyon, J. Phys. Oceanogr., 32, 1890-1913, doi:10.1175/1520-0485(2002)032<1890:IWIMSC>2.0.CO;2.

Lee, O. S. (1961), Observations on internal waves in shallow water, Limnol. Oceanogr., 6, 312-321, doi:10.4319/lo.1961.6.3.0312.

Leichter, J. J., S. R. Wing, S. L. Miller, and M. W. Denny (1996), Pulsed delivery of subthermocline water to Conch Reef (Florida Keys) by internal tidal bores, Limnol. Oceanogr., 41, 1490-1501, doi:10.4319/lo.1996.41. 7.1490 .

Lucas, A. J., P. J. S. Franks, and C. L. Dupont (2011), Horizontal internaltide fluxes support elevated phytoplankton productivity over the inner continental shelf, Limnol. Oceanogr. Fluids Environ., 1, 56-74.

McPhee-Shaw, E., D. A. Siegel, L. Washburn, M. A. Brzezinski, J. L. Jones, A. Leydecker, and J. Melack (2007), Mechanisms for nutrient delivery to the inner shelf: Observations from the Santa Barbara Channel, Limnol. Oceanogr., 52, 1748-1766, doi:10.4319/lo.2007.52.5.1748.

Monismith, S. G., and D. A. Fong (1996), A simple model of mixing in stratified tidal flows, J. Geophys. Res., 101, 28,583-28,595, doi:10.1029/ 96JC02267

Nam, S., and U. Send (2011), Direct evidence of deep water intrusions onto the continental shelf via surging internal tides, J. Geophys. Res., 116, C05004, doi:10.1029/2010JC006692.

Osborn, T. R. (1980), Estimates of the local rate of vertical diffusion from dissipation measurements, J. Phys. Oceanogr., 10, 83-89, doi:10.1175/ 1520-0485(1980)010<0083:EOTLRO >2.0.CO;2.
Petruncio, E. T., L. K. Rosenfeld, and J. D. Paduan (1998), Observations of the internal tide in Monterey Canyon, J. Phys. Oceanogr., 28, 1873-1903, doi:10.1175/1520-0485(1998)028<1873:OOTITI $>2.0$.CO;2.

Pineda, J. (1991), Predictable upwelling and the shoreward transport of planktonic larvae by internal tidal bores, Science, 253, 548-549, doi:10.1126/science.253.5019.548.

Pineda, J. (1994), Internal tidal bores in the nearshore: Warm-water fronts, seaward gravity currents and the onshore transport of neustonic larvae, J. Mar. Res., 52, 427-458, doi:10.1357/0022240943077046.

Pineda, J. (1995), An internal tidal bore regime at nearshore stations along western USA: Predictable upwelling within the lunar cycle, Cont. Shelf Res., 15, 1023-1041, doi:10.1016/0278-4343(95)80007-Z.

Pineda, J. (1999), Circulation and larval distribution in internal tidal bore warm fronts, Limnol. Oceanogr., 44, 1400-1414, doi:10.4319/1o.1999. 44.6.1400.

Pope, S. B. (2000), Turbulent Flows, 771 pp., Cambridge Univ. Press, Cambridge, U. K, doi:10.1017/CBO9780511840531.

Rosman, J. H., J. L. Hench, J. R. Koseff, and S. G. Monismith (2008), Extracting Reynolds stresses from acoustic Doppler current profiler measurements in wave-dominated environments, J. Atmos. Oceanic Technol. 25, 286-306, doi:10.1175/2007JTECHO525.1.

Scotti, A., and J. Pineda (2004), Observation of very large and steep internal waves of elevation near the Massachusetts coast, Geophys. Res. Lett., 31 L22307, doi:10.1029/2004GL021052.

Shea, R. E., and W. W. Broenkow (1982), The role of internal tides in the nutrient enrichment of Monterey Bay, California, Estuarine Coastal Shelf Sci., 15, 57-66, doi:10.1016/0272-7714(82)90036-1.

Shih, L. H., J. R. Koseff, G. N. Ivey, and J. H. Ferziger (2005), Parameterization of turbulent fluxes and scales using homogeneous sheared stably stratified turbulence simulations, J. Fluid Mech., 525, 193-214, doi:10.1017/S0022112004002587.

Shroyer, E. L., J. N. Moum, and J. D. Nash (2009), Observations of polarity reversal in shoaling nonlinear internal waves, J. Phys. Oceanogr., 39, 691-701, doi:10.1175/2008JPO3953.1.

Smyth, W. D., J. N. Moum, and J. D. Nash (2011), Narrowband oscillations in the upper Equatorial ocean. Part II: Properties of shear instabilities, J. Phys. Oceanogr., 41, 412-428, doi:10.1175/2010JPO4451.1.

Stoker, J. J. (1948), The formation of breakers and bores: The theory of nonlinear wave propagation in shallow water and open channels, Commun. Pure Appl. Math., 1, 1-87, doi:10.1002/cpa.3160010101.

Storlazzi, C. D., M. A. McManus, and J. D. Figurski (2003), Long-term, high-frequency current and temperature measurements along central California: Insights into upwelling/relaxation and internal waves on the inner shelf, Cont. Shelf Res., 23, 901-918, doi:10.1016/S0278-4343(03) 00045-1.

Venayagamoorthy, S. K., and O. B. Fringer (2007), On the formation and propagation of nonlinear internal boluses across a shelf break, J. Fluid Mech., 577, 137-159, doi:10.1017/S0022112007004624.

Walter, R. K., N. J. Nidzieko, and S. G. Monismith (2011), Similarity scaling of turbulence spectra and cospectra in a shallow tidal flow, J. Geophys. Res., 116, C10019, doi:10.1029/2011JC007144.

Wolanski, E., and G. Pickard (1983), Upwelling by internal tides and kelvin waves at the continental shelf break on the Great Barrier Reef, Mar. Freshwater Res., 34, 65-80, doi:10.1071/MF9830065.

Wong, S. H. C., A. E. Santoro, N. J. Nidzieko, J. L. Hench, and A. B Boehm (2012), Coupled physical, chemical, and microbiological measurements suggest a connection between internal waves and surf zone water quality in the Southern California Bight, Cont. Shelf Res., 34, 64-78, doi:10.1016/j.csr.2011.12.005.

Woodson, C. B., L. Washburn, J. A. Barth, D. J. Hoover, A. R. Kirincich, M. A. McManus, J. P. Ryan, and J. Tyburczy (2009), Northern Monterey Bay upwelling shadow front: Observations of a coastally and surfacetrapped buoyant plume, J. Geophys. Res., 114, C12013, doi:10.1029/ 2009JC005623

Woodson, C. B., et al. (2011), Observations of internal wave packets propagating along-shelf in northern Monterey Bay, Geophys. Res. Lett., 38 L01605, doi:10.1029/2010GL045453. 